have been cured by these manipulations without recourse to a cutting operation. I cannot state at the present moment how many such patients I have dealt with, but I should think at least 30 and probably more.

In THE LaNCET of June 13th, 1891, you were good enough to publish an article by me upon this subject, in which I gave the subsequent histories of the patients whose cases I had recorded eight years previously, showing that the treatment had been permanent in its effects. I do not assume that all cases of internal derangement of the knee-joint can be cured without operation - in fact, it seems evident from certain recorded post-mortem examinations of such joints that open operation must sometimes be necessary, nor do I suggest that in Mr. Owen's case any other treatment than that which he adopted would have been successful. I simply wish to controvert his statement that nothing short of a cutting operation will put such a knee right. The only alternative treatment which he refers to is " the use of splints, knee-trusses, and pads, or retentive apparatus," and further he remarks that such treatment would cripple the limb and interfere with exercise. The treatment which was successful in a large number of cases in the hands of William Hey, and following him Samuel Smith, both of Leeds, and Samuel Hey (grandson of William), Astley Cooper, Syme, and Sir Benjamin Brodie does not involve fixation of the joint, or at least in my experience fixation of the joint is not necessary. On the contrary, I have found that when the cartilage seems to have slipped back into its place after manipulation we can allow the patient to walk about, simply cautioning him to avoid any careless lateral movements. In a few cases I have used temporarily a light apparatus which allows perfect freedom for flexion and extension of the leg but checks any Iateral movement. This apparatus was, I believe, devised or at least used by the late Sir James Paget.

Mr. Owen's excellent remarks upon the seriousness of the operation which he advocates should, I think, induce surgeons to give a thorough trial to manipulative treatment before resorting to a serious operation. There exist undoubtedly many instances in which new growths have formed in the joint or in which so much damage has been occasioned that an operation is imperative, but there is, I contend, ample evidence to show that in the majority of cases of displacement of the internal semilunar cartilage a milder and perfectly safe treatment by manipulation will effect a cure. It must, however, be understood that replacement by one manipulation, if it can be effected, is not sufficient to cure the case. Passive movements of the knee-joint must be repeated again and again, probably for several weeks, to ensure the retention of the cartilage in its normal position.

I am, Sirs, yours faithfully, NOBLE SMITH.

Queen Anne-street, London, W., April 30th, 1900.

\section{"THE FOUR-THOUSANDTH NUMBER OF THE LANCET."}

To the Editors of THE LANCET.

SIRS,-The four-thousandth number of THE LANCET comes to me with especial interest, for my father, brother, and myself have never missed a number since its commencement. This is a fact that I think few members of our profession can record, or that a father and two sons should have been in daily practice in the same town for a space of 87 years -10 years before the first number of THE LANCET appeared. I I am, Sirs, yours faithfully,

Ringwood, Hants, April 30th, 1900 .

H. Geary Dyer, M.D. Durh.

\section{"THE NITRO-PROPIOL TEST FOR SUGAR IN URINE."}

To the Editors of THE LANCET.

SIRS,--Since you drew attention to the above test in THF LANCET of Feb. 17th, 1900, I have largely experimented with nitro-propiol and there can be no doubt that the reaction is of a most striking and convincing nature. As Dr. Saundby in his letter on the same subject has pointed out, Fehling's solution is reduced by a number of other bodies besides sugar and it would hardly be safe to pronounce a patient to suffer from glycosuria upon this test alone without resorting to control tests. There is only one body which is liable to interfere with the nitro-propiol reaction (viz., aldehyde) and this body is not a constituent of the urine; nitro-propiol therefore seems to be particularly appropriate for the qualitative determination of sugar in urine. Whether aldehyde was formed by the filtration of the urine through animal charcoal in the case which Dr. Saundby refers to in his letter is a question to be considered. Nitropropiol will indicate such small percentage of sugar which entirely escapes observation in the fermentation test and which can only with difficulty be proved by the phenylhydrazine or the osozone test respectively. The importance which must be placed upon the minutest waste of sugar in the body, if it occur regularly and not temporarily, should render nitro-propiol a most valuable reagent. I do not agree with the directions for the application of the test as given on the labels. Diabetic urine or even a very dilute solution of glucose (I have experimented with solutions containing 0.06 per cent. of glucose only) produces the reaction within 30 or 40 seconds after the tablet has been dissolved and after the test liquid has reached the boiling point. Continued boiling for from three to five minutes is, therefore, not a compulsory, but only a precautionary, measure for proving the absence of sugar. The propiol test can just as well be carried out in a test-tube as Fehling's test (I use a larger size tube, holding it by a paper loop), because the reaction is almost an instantaneous one, in case of diabetic urine, whilst in cases of non-diabetic urine gentle boiling for a few minutes is quite sufficient to prove the absence of sugar. The complete absence of the distasteful odour developed by Fehling's test is another point in favour of propiol. As the new test will meanwhile have attracted considerable attention I am looking forward with interest to the expression of further opinions on the subject. My belief is that it will prove a boon to the general practitioner on account of its simplicity, reliability, and stability.

Lee, S.E., April 24th, 1900. I am, Sirs, yours faithfully,

\section{TYPHOID FEVER IN THE SOUTH AFRICAN FIELD FORCE.}

To the Editors of THE LANowT.

SIRS,- - When General Buller entered Ladysmith he saw a cemetery containing no less than 700 graves of men who died from enteric fever. In other parts of Africa the disease has given rise to an equally large mortality. Hundreds of our men were inoculated with anti-typhoid serum before leaving home. Are there any statistics or reliable facts to be obtained yet which bear on the relation between cases of the disease and the number of inoculations made? In some cases whole regiments were injected to a man, and as records of the cases of enteric fever are kept we should be in a position to judge somewhat of the value of the anti-typhoid serum.

I am, Sirs, yours faithfully,

MARTYN WESTCOTT, L.R.C.P. Lond, \&c.

East Suffolk Hospital, Ipswich, Suffolk.

\section{NOTES FROM INDIA.}

\section{(From oUR SPECIAL CORRESPONDENT.)}

The Unhealthiness of Assam.-The Health of British Troops in India.-Spurious Typhoid Fever.-The Plague in Calcutta and Bombay. - The Pasteur Institution of India.

THE extraordinary unhealthiness of 'some parts of Assam which was lately commented upon by the Viceroy is fully detailed in the last administration report. In the Surma Valley, which is estimated to contain about $2,500,000$ people, there were only 75,000 births in 1898 , but 94,000 deaths. Also in the Assam Valley there were only 71,031 births, while there were registered 85,000 deaths. There was a decline in the birth-rate throughout the province. This is attributed to the outbreak of malarial (?) fever added to the privations endured subsequently to the earthquake. The most unhealthy district was Nowgong, which had a birth-rate of 18.66 per 1000 , while its death-rate was 47.25 . There is little doubt that defective registration largely accounts for these low birth-rates, but the death-rates are probably very near the mark. Ordinary fever and cholera showed a decline, but the disease known as kala azar is reported to have carried off 16,000 victims.

The annual report of the Sanitary Commissioner with the 